\title{
Current and future therapeutic approaches in idiopathic pulmonary fibrosis
}

\author{
D. Bouros* and K.M. Antoniou\#
}

ABSTRACT: Idiopathic pulmonary fibrosis (IPF) is a lethal form of idiopathic diffuse lung disorders for which no current treatment is effective. The aim of the present study was to systematically review the current status and novel therapies of IPF, with emphasis on controlled trials.

The studies selected included randomised controlled trials using drugs alone and/or in combination for the treatment of adults with IPF and meta-analyses, published in English. Abstracts of identified articles were retrieved and articles possibly fulfilling inclusion criteria were retrieved in full. Two reviewers independently assessed trial quality if there were any included studies. Data quality was based on place of publication and relevance to clinical care.

There is a lack of good-quality studies regarding the effectiveness of the most used drugs, including corticosteroids and noncorticosteroid immunosuppressive agents. Oral corticosteroids are the usual treatment. Other therapies either alone or in combination with corticosteroids are widely used, including azathioprine, cyclophosphamide and colchicine. Interestingly, clinical trials with novel drugs, mainly antifibrotic, anticytokine and immunoregulatory, are currently being investigated in various trial phases.

In conclusion, at present, there are no evidence-based therapies for idiopathic pulmonary fibrosis. Further controlled studies are warranted to improve the evidence base for clinical practice.

KEYWORDS: Idiopathic pulmonary fibrosis, interstitial lung diseases, therapy

I diopathic pulmonary fibrosis (IPF), also termed cryptogenic fibrosing alveolitis (CFA), is the most common of the seven disease entities of the idiopathic interstitial pneumonias (IIPs), constituting more than half of cases [1-5]. IPF is a specific form of chronic fibrosing interstitial pneumonia of unknown aetiology, limited to the lung. The estimated incidence is $7-11$ cases per 100,000 and the estimated prevalence 27-29 per 100,000 [4]. Cardinal symptoms include dry cough and exertional dyspnoea becoming progressively worse over several months, while physical examination reveals basilar, end-inspiratory "cellophane" or "velcro" rales in $>80 \%$ of patients. Restrictive pulmonary function and exerciserelated hypoxaemia are part of the clinical picture. Clinically, IPF must be distinguished from the other IIPs. A definitive diagnosis requires surgical lung biopsy, but a confident diagnosis can be affirmed in typical cases using the recently established criteria [1]. The most difficult differential is often between nonspecific interstitial pneumonia (NSIP) and IPF.

A high-resolution computed tomography (HRCT) scan of the thorax is essential for diagnosis and follow-up. Typical HRCT scans and clinical evaluation can assist experienced clinicians in making a confident diagnosis without the need for biopsy [1-3]. According to recent recommendations of the American Thoracic Society/European Respiratory Society (ATS/ ERS) [1], the sine qua non pathological pattern of IPF is that of usual interstitial pneumonia (UIP). IPF is characterised by a UIP pattern that varies in severity throughout the lung. The histological hallmark of IPF, the fibroblastic focus, is rare or absent in NSIP. Furthermore, the lesions in NSIP are often remarkably uniform throughout the lung. The patterns on HRCT can also sometimes distinguish the conditions [6]. Patients with a HRCT scan that is typical for UIP and histological UIP have a significantly worse prognosis than those with a histological UIP and atypical HRCT scan [7].
AFFILIATIONS

*Dept of Pneumonology, Medical School, Democritus University of Thrace, Alexandroupolis, and \#Dept of Thoracic Medicine, University Hospital of Heraklion, Crete, Greece.

CORRESPONDENCE

D. Bouros

Medical School

Democritus University of Thrace

Alexandroupolis 68100

Greece

Fax: 302551076106

E-mail: bouros@med.duth.gr

Received:

December 182004

Accepted after revision: April 042005

\section{SUPPORT STATEMENT}

This study was supported by the Society for Respiratory Research at the University of Thrace, Alexandroupolis, Greece. 
It has been proposed that UIP/IPF represents a distinct disease process/entity that is separate from other IIPs, largely based on the paucity of "inflammation" on UIP histology and unresponsiveness to conventional therapy with antiinflammatory agents [8, 9]. Recent studies demonstrate, however, that different histopathological patterns of IIP cOexist in the same patient and even in the same lobe of the lung [10]. In cases where multiple biopsies were available for evaluation, discordance among the biopsies was often present [10]. Of note, the prognosis is still predicted by the histology, with the uniform (NSIP-like) cases having the best prognosis.

The overall survival resembles that for patients with lung cancer [11]. Most IPF patients die within 3-8 yrs from the onset of symptoms, with a mean survival of 2.5-3.5 yrs (5-yr survival range $30-50 \%$ ) [12-17].

Therapy of IPF is highly controversial and mostly ineffective. Initial pathogenetic theory considered IPF as a result of an unidentified insult initiating the cycle of chronic inflammation leading to fibrosis. Making the assumption that interrupting the inflammatory cascade before irreversible parenchymal injury occurs, fibrosis might be alleviated and anti-inflammatory therapy seemed reasonable. Traditionally, corticosteroids, immunosuppressive or cytotoxic agents have been used. However, it is now clear that these treatment options are of unproven benefit and have potentially serious side-effects. All of the prior studies had serious flaws, which have been alluded to in multiple publications. A recent consensus statement [1] suggests that a trial of therapy is reasonable for patients with clinical or physiological impairment or a deteriorating course. The ATS/ERS international consensus statement recommends combined therapy (corticosteroid and either azathioprine (AZA) or cyclophosphamide (CP)) for initial treatment of those patients with IPF who have been given adequate information regarding the merits and pitfalls of treatment, and who possess features consistent with a more likely favourable outcome [1]. In this context, both the ATS and ERS recommend combining an immunosuppressive agent, AZA or CP $\left(2-3 \mathrm{mg} \cdot \mathrm{kg} \cdot \mathrm{day}^{-1}\right)$, with prednisone or prednisolone $\left(0.5 \mathrm{mg} \cdot \mathrm{kg} \cdot \mathrm{day}^{-1}\right.$ for 4 weeks) with gradual taper [1]. However, this statement concludes that existing therapies for IPF are of unproven benefit, emphasising the need to develop novel therapies.

It appears that this is a critical time in the study and treatment of IPF. Current understanding of the pathogenesis and natural history of the disease continues to grow. Although there is, as yet, no demonstrated effective treatment for IPF, there are a number of promising candidates. Lessons from previous clinical trials will be very helpful in the evaluation of these agents and perhaps the need for multimodality therapy. Various potential therapies might be effective in countering each pathogenic stage.

Furthermore, contrasts in outcomes and interpretation of recent studies underscores the importance of study design in choosing appropriate and valid end points. The necessity of "pathotherapeutic" linkage in the design of future studies also seems important. Therefore, it is incumbent on all pulmonologists to direct IPF patients to clinical trials so that answers can hopefully be provided.
The objective of the present study was to systematically review the current status and the novel therapies of IPF, with emphasis on controlled trials.

\section{METHODS}

Peer-reviewed publications were identified through MEDLINE (January 1966-July 2004), EMBASE (January 1973-July 2004), the Cochrane Central Register of Controlled Trials (The Cochrane Library Issue 3, 2004), and references from bibliographies of relevant articles.

Each drug was searched in combination with the term IPF or CFA. Criteria used for study selection included controlled study design, English language and validity based on power analysis and venue of publication.

\section{DATA SYNTHESIS}

The high-quality controlled clinical trials of pharmacological therapy in IPF are summarised in table 1.

\section{Anti-inflammatory drugs}

\section{Corticosteroids}

Although corticosteroids have been considered the mainstay of IPF treatment for decades, there are no controlled trials using corticosteroids alone for the treatment of IPF [24]. Therefore, any conclusive evidence supporting the use of corticosteroid therapy for the treatment of IPF is lacking. A review of a series of noncontrolled trials showed that the short-term improvement in pulmonary function did not affect the 3-5-yr survival [25]. Since these early studies that report responses of $10-30 \%$ with corticosteroids given alone or in combination with immunosuppressives precede the current classification of IIP, it is possible to include cases of IIP responsive to corticosteroids, such as NSIP, desquamative interstitial pneumonia, respiratory bronchiolitis-associated interstitial lung disease or cryptogenic organising pneumonia, which are considered steroid responsive. When anti-inflammatory agents were given in pure cases of IPF, there was no evidence of significant response [24]. Therefore, it is crucial to make an accurate diagnosis in each patient.

Early treatment with corticosteroids, when active inflammation is present, has been suggested to be associated with a better outcome [25]. Given the serious adverse effects and the lack of any evidence for a dose-response effect, the primum non nocere principle for the high doses of corticosteroids should be kept in mind.

\section{Cytotoxic and immunosuppressive agents}

AZA and CP are the most frequently used second-line drugs, usually in combination with corticosteroids. There is little good-quality information regarding the efficacy of cytotoxic and immunosuppressive agents in IPF/UIP. Currently, there is little to justify the routine use of any of them in the management of IPF/UIP [26].

\section{Azathioprine}

AZA is a well-tolerated cytotoxic agent widely used in the management of IPF. Although a number of studies have investigated the use of this agent, there are only three randomised controlled trials in the literature [19, 20, 27], only one of which is of high methodological quality [19]. The trial 
TABLE 1 Controlled clinical trials of pharmacological therapy in idiopathic pulmonary fibrosis (IPF)

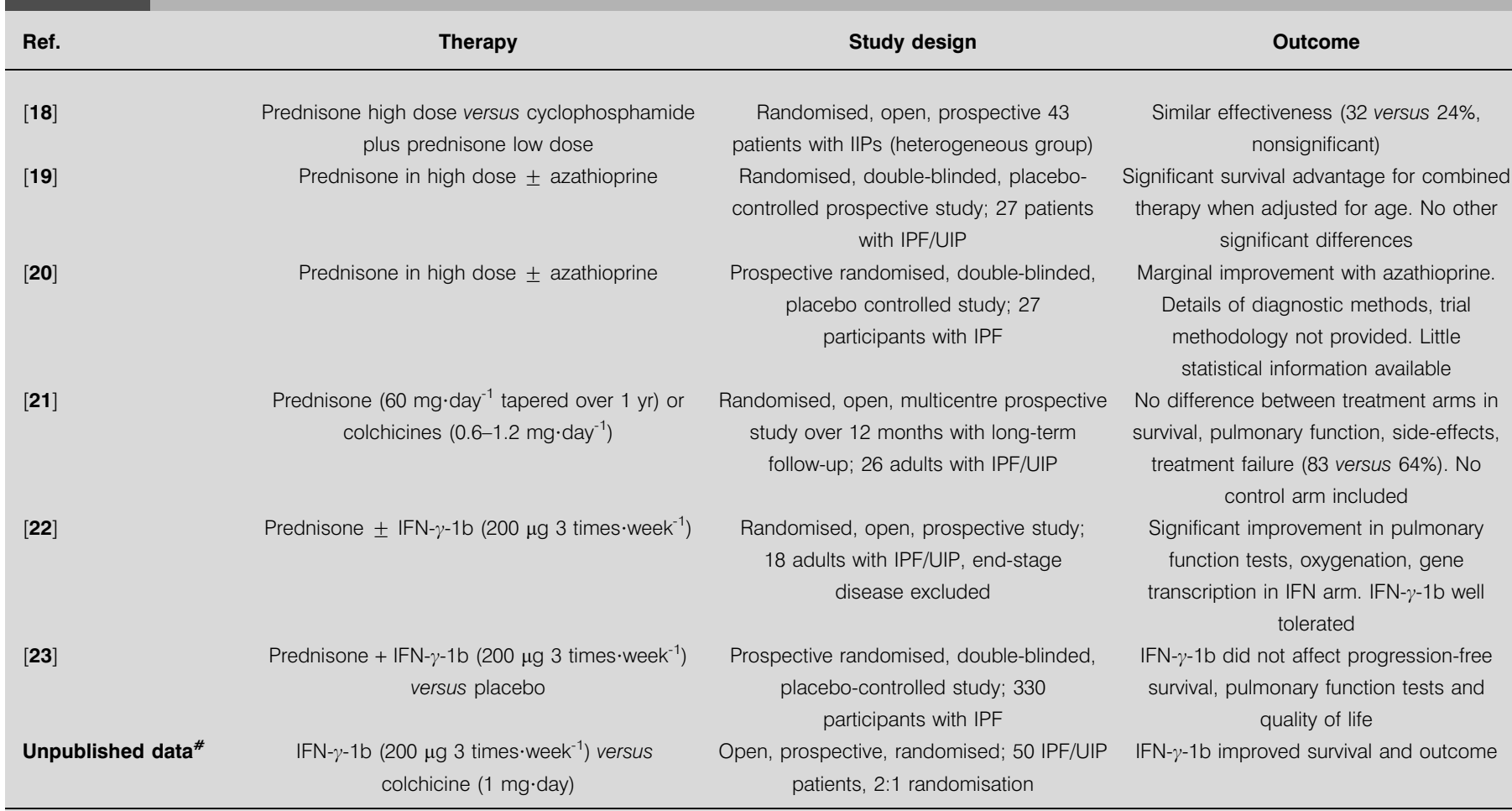

IIP: idiopathic interstitial pneumonia; UIP: usual interstitial pneumonia; IFN: interferon. ${ }^{\#}$ : K.M. Antoniou, et al., Dept of Thoracic Medicine, University Hospital of Heraklion, Crete, Greece.

by FULMER et al. [27] contained inadequate data as it was only published in abstract form. This study failed to show significant difference between therapies. The second randomised controlled trial of lesser quality showed some marginal benefit by adding AZA to prednisone [19]. The study by RAGHU et al. [19] showed a small, but statistically significant, long-term survival advantage for AZA once allowances were made for age differences.

There are several uncontrolled, nonrandomised and often poor methodological studies combining AZA with corticosteroids reporting responses in the therapy of IPF and sometimes with other agents, most frequently cyclophosphamide or Dpenicillamine. A firm conclusion cannot be derived from these studies [28-35].

Based upon the limited data available, there appears to be little benefit achieved from the addition of AZA to oral corticosteroid therapy in the treatment of IPF. There does not appear to be a significant therapeutic or steroid-sparing effect. However, it may give a long-term, minor survival advantage. Although the data are insufficient to show a clear additive effect of AZA, given its better adverse effects profile compared with $\mathrm{CP}$, many experts and the aforementioned guidelines propose a 6month trial of oral AZA in patients with symptomatic or progressive disease [1].

\section{Cyclophosphamide}

$\mathrm{CP}$ is frequently used as a second-line drug for patients that either have failed or presented adverse effects from short- or long-term corticosteroid therapy. However, there is little evidence available in the literature to support its use. The overall experience from several small published case series [32, 36-45] and from the only randomised comparative study [18] has been disappointing. The study by JOHNSON et al. [18] was methodologically flawed and, since it has been contacted before the current classification of IIP, contained patients with other forms. Intravenous, rather than oral, cyclophosphamide failed to demonstrate additional benefit $[35,36,38]$. In a retrospective study, COLLARD et al. [46] compared combination corticosteroid and CP therapy in a large population of patients who met the current consensus definition of IPF. No survival difference was found between patients who were treated or untreated $(p=0.58)$. In a recent published study, the authors compared the efficacy of CP combined with low-dose prednisolone in the treatment of IPF (27 patients) with efficacy in idiopathic fibrosing NSIP (12 patients). It has been reported that patients with fibrosing NSIP had a more favourable response to combination therapy and a better survival than those with IPF [47]. Therefore, given its serious toxicities and its limited, if any, efficacy, CP is not recommended as therapy for IPF.

\section{Cyclosporine}

Cyclosporine has rarely been used as an adjunct in the management of IPF and in reducing the dose of oral corticosteroids in participants awaiting lung transplantation. There is no good evidence showing that cyclosporine therapy is of benefit. No controlled clinical trials exist. However, there 
are a number of uncontrolled studies in the literature [48-52], but the trials are of poor methodological quality and often contain participants with heterogeneous diseases. The optimal dose of cyclosporine is unknown.

\section{Mycophenolate mofetil}

Although this drug is a potent immunosuppressive and there is a reasonable hypothesis for activity in IPF [53], it has not yet been evaluated. However, cases of pulmonary fibrosis following administration of this drug $[54,55]$ have been reported.

\section{Other cytotoxic chemotherapeutic agents}

Methotrexate has been used rarely, probably because of its known pulmonary toxicity $[56,57]$. Methotrexate-induced lung injury is difficult to distinguish from progression of the underlying disease. Chlorambucil or vincristine have only been used once each in a case report $[20,40]$.

New concepts in pathogenesis and implications for management in IPF

Historically, it was believed that UIP was the end result of all IIPs. However, it is currently clear that UIP is distinguishable from the other forms of IIP with prognostic and therapeutic implications. It was long believed that IPF was the result of a repeated unknown insult to lung parenchyma, leading to inflammation and eventually to diffuse pulmonary fibrosis, loss of the architectural structure and progressive deterioration in pulmonary function [16]. Although this hypothesis seems true for other corticosteroid-responsive IIPs and diffuse parenchymal lung diseases, it is unlikely that this is the case in IPF. In support of this is the poor responsiveness of IPF to anti-inflammatory drugs, such as corticosteroids. According to the current pathophysiological theory, IPF/UIP is the result of continuing patchy alveolar epithelial injury and abnormal wound healing [9, 17]. Alveolar epithelial cells are hypertrophic/hyperplastic, with phenotypic alterations and expression of profibrotic cytokines and growth factors that are implicated in IPF pathogenesis [58-63]. These cells may also be involved in the production of: tissue factor and plasminogen activator inhibitor-I; decreased plasmin and increased fibrin deposition; lack of activation of matrix metalloproteinases responsible for extracellular matrix degradation; impaired epithelial cell migration; and increased fibroblast proliferation [64-66].

Fibroblast/myofibroblast foci to sites of lung injury, decreased myofibroblast apoptosis [67] and increased activity of end response to fibrogenic cytokines [68] are characteristic features of IPF/UIP. It is recognised that fibroblasts/myofibroblasts can maintain their activity and growth in the absence of inflammatory cells [69] via epithelial autocrine mechanisms. The possible pathogenetic role of circulating fibrocytes has recently been suggested [70].

\section{NOVEL APPROACHES TO THERAPY Immunomodulators}

Recent clinical trials suggest that targeting the "fibroproliferative" process, and not the inflammatory pathway, may be more promising. However, novel biological antifibrotic drugs, such as interferon- $\gamma-1 b(\operatorname{IFN}-\gamma-1 b)$, appear as effective therapy in a subset of patients.
Interferon- $\gamma-1 b$

IFN- $\gamma$ is an inflammatory cytokine with a number of inhibitory effects on fibroblasts. In a small pilot-controlled study of 18 IPF patients, ZIESCHE et al. [22] found a favourable response in both molecular and clinical aspects. These cases have been extensively reviewed and are felt to be true IPF cases [71]. Recently, RAGHU et al. [23] randomly assigned 330 patients with unresponsiveness to corticosteroid therapy to receive either IFN- $\gamma-1 \mathrm{~b}\left(200 \mu \mathrm{g}\right.$ three times $\cdot$ week $\left.\cdot \mathrm{s}^{-1}\right)$ or placebo. No statistically significant differences were observed in the primary outcome variables (disease progression), mortality and functional deterioration. However, there was a strong trend $(p=0.08)$ towards better survival with treatment. A survival benefit $(p=0.04)$ was found in patients with mild-to-moderate disease (forced vital capacity (FVC) above the median $>62 \%$ predicted) [23].

Furthermore, a recently published study found changes after IFN- $\gamma-1 b$ treatment primarily in angiogenic biomarkers (CXCL11 and epithelial neutrophil-activating protein-78, ENA-78), but not in transforming growth factor (TGF)- $\beta$ or connective tissue growth factor (CTGF), suggesting that IFN- $\gamma$ $1 b$ may affect IPF through multiple pathways [72]. Additionally, the present authors found increased levels of the angiogenic cytokine interleukin (IL)-18 in IPF patients in comparison with healthy controls, but no differences at the level of Th1 cytokines (IL-12 and IL-18) in the bronchoalveolar lavage fluid (BALF) between the two treatment groups (IFN- $\gamma$ $1 \mathrm{~b}$ or colchicine) after 12 months of treatment [73].

It was recently reported that physiological change is an imperfect predictor of mortality and that survival is the most appropriate end point for future studies [74]. It is possible, therefore, that efficacy using IFN- $\gamma-1 b$ may be demonstrable in a study with a different design. This apparent survival difference is the subject of a phase III multicentre international trial, enrolling 600 patients to assess the impact of IFN- $\gamma-1 \mathrm{~b}$ on overall survival. The trail is entitled INSPIRE.

\section{Antifibrotic agents}

\section{Colchicine}

Colchicine inhibits the secretion of collagen and a number of other important growth factors necessary for fibroblast proliferation, as well as the release of mediators responsible for the development of fibrosis, fibronectin and alveolarmacrophage-derived growth factor. These effects have formed the basis for a number of clinical trials in patients with IPF. There are two retrospective studies $[75,76]$, one prospective, nonrandomised study [77] and one good-quality, randomised, controlled trial [21]. The only randomised, controlled, open trial [76] compared 26 patients treated with either colchicine $0.6-1.2 \mathrm{mg} \cdot \mathrm{day}^{-1}(\mathrm{n}=14)$ or prednisone $(n=12)$ for 12 months. Follow-up was for up to 2.5 yrs. In most subjects with typical clinical and HRCT features of idiopathic UIP, neither prednisone nor colchicine resulted in objective improvement, and the disease continued to progress in the majority. Colchicine appears to be a safer alternative to a trial of highdose prednisone, but may be no different than no therapy. With the present limited data, there is no evidence to suggest a beneficial role for colchicine in the treatment of IPF. 


\section{D-penicillamine}

D-penicillamine inhibits collagen turnover, collagen synthesis and attenuates collagen deposition by interrupting crosslinking of collagen molecules [78].

Although D-penicillamine has been extensively used in the therapy of IPF, good-quality controlled trials do not exist. Several open-label, nonrandomised uncontrolled trials or case series, which were adequate methodologically [28, 30, 35, 7982] failed to show any benefit. Given the present evidence of benefit and the frequent side-effects, D-penicillamine does not appear to be a treatment choice in IPF.

\section{Pirfenidone}

Pirfenidone is an orally taken, well-tolerated drug, apart from some gastro-intestinal side-effects and photosensitivity. In vitro evidence has shown that pirfenidone inhibits collagen synthesis, downregulates pro-fibrotic cytokines and decreases fibroblast proliferation in vitro through TGF- $\beta$-mediated effects [83].

There are no randomised controlled trials examining the role of pirfenidone in patients with IPF. There is one prospective, open-label, phase II trial [84], and one case series study [85] showing some encouraging data.

The results of a double-blind, randomised, placebo-controlled study of 107 patients with IPF have recently been published recently by AzUMA et al. [86]. The primary end point was the difference in the change in the lowest oxygen saturation by pulse oximetry during a 6-min exercise test, from baseline to 6 months. The authors did not find any statistically significant difference between the two groups $(p=0.072)$. However, positive treatment effect with pirfenidone was demonstrated in secondary end points, such as vital capacity and prevention of acute exacerbation of IPF.

\section{Angiotensin-converting enzyme inhibitors and statins}

Angiotensin-converting enzyme inhibitors (ACEI) and statins (3-hydroxy-3-methylglutaryl coenzyme-A reductase inhibitors) have been shown to possess antifibrotic properties in experimental models in vitro and in vivo. In a retrospective review [87] of the effects of survival of 52 patients receiving ACEI and 35 patients receiving statins, there was no significant difference in survival between patients with IPF receiving either ACEI or statins versus those receiving neither at the index visit (2.5 yrs versus 3 yrs, respectively; $\mathrm{p}=0.066$ ).

\section{Antioxidants}

$\mathrm{N}$-acetylcysteine

$\mathrm{N}$-acetylcysteine has antioxidant properties and replenishes glutathione in the lungs of patients with different mechanisms of action, including decreasing fibroblastic and extracellular matrix deposition, as well as reducing inflammation [88]. Studies have shown that N-acetylcysteine elevates BALF levels of glutathione in IPF patients, but not in healthy controls [89]. There are no published randomised controlled trials to assess the role of $\mathrm{N}$-acetylcysteine in IPF. There is only one shortterm, prospective, open-label, uncontrolled trial in a group of $10 \mathrm{IPF}$ patients [90].

A randomised, double-blind, placebo-controlled trial was recently completed in seven European countries. In the present study, oral $\mathrm{N}$-acetylcysteine $\left(1,800 \mathrm{mg} \cdot \mathrm{day}^{-1}\right)$ has been added to conventional therapy with prednisone $\left(0.5 \mathrm{mg} \cdot \mathrm{kg} \cdot \mathrm{day}^{-1}\right)$ plus AZA $\left(2 \mathrm{mg} \cdot \mathrm{kg} \cdot \mathrm{day}^{-1}\right)$. The primary end point was a change in the FVC and carbon monoxide diffusing capacity of the lung $(D \mathrm{~L}, \mathrm{CO})$. Of the 184 patients enrolled, 155 qualified for the final analysis. There was a significant difference in the rate of decline in both parameters in favour of the N-acetylcysteine group. However, there was no difference in the mortality between the two groups. Therefore, this appears to have been a positive study based on the primary end points chosen.

\section{Clinical trials under way}

Given the lack of effective treatment, there is a major need for additional high-quality randomised controlled clinical trials to evaluate evolving and potential therapeutic agents in the therapy of IPF. A number of early-phase interesting clinical trials are currently under way (table 2).

\section{Endothelin receptor 1 antagonist}

The endothelial cell-derived endothelin-1 (ET-1) is a potent mitogen for endothelial cells, vascular smooth muscle cells and tumour cells. ET-1 is strongly upregulated in IPF lungs and is mainly expressed in epithelial cells. Some studies have suggested that inhibition of this mediator could have antifibrotic effects [91, 92]. In addition, it has recently been

TABLE 2 Ongoing clinical trials with novel drugs for idiopathic pulmonary fibrosis

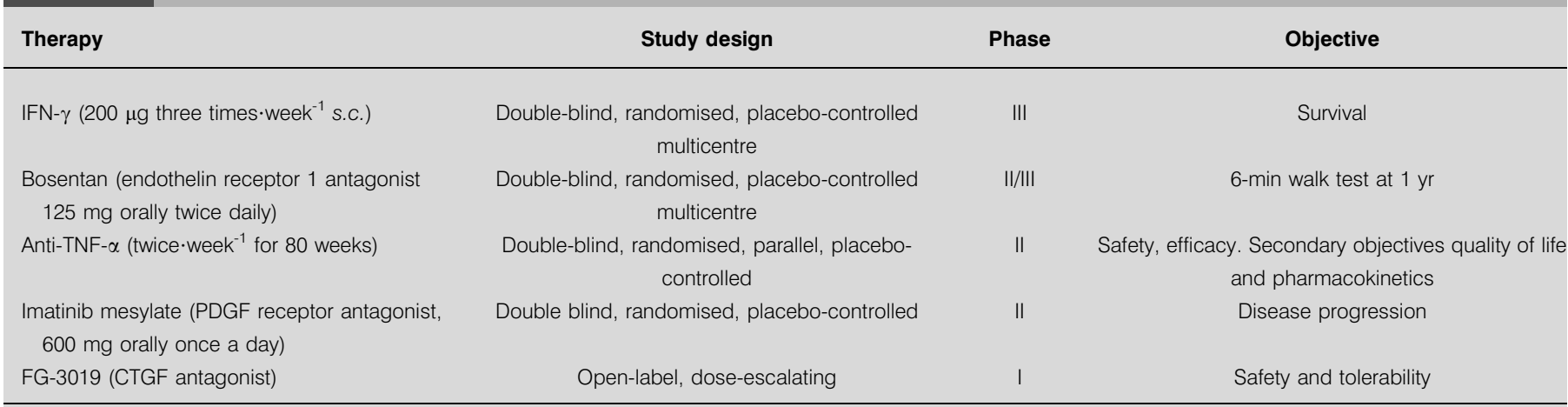

INF: interferon; TNF: tumour necrosis factor; PDGF: platelet-derived growth factor; CTGF: connective tissue growth factor. 
demonstrated that ET-1 and its receptors act as angiogenic regulators representing new targets for anti-angiogenic therapy [93].

Bosentan, a nonselective ET (A) and ET (B) receptor antagonist, has been used extensively in patients with primary pulmonary hypertension and World Health Organization class III and IV [94], and could delay the progression of IPF.

Currently, bosentan is being studied in two double-blind randomised, placebo-controlled, multicentre phase II/III studies, of 12 months, duration for its efficacy, safety and tolerability in IPF (Bosentan Use in Interstitial Lung Disease (BUILD)-1) and pulmonary fibrosis associated with systemic sclerosis (BUILD2). The primary end point of both trials will be the 6-min walk test at $1 \mathrm{yr}$. Secondary end points are the pulmonary function tests and the patients' quality of life.

\section{Tumour necrosis factor- $\alpha$ blockade}

Tumour necrosis factor (TNF)- $\alpha$ has been found to be significantly elevated in bleomycin-induced pulmonary fibrosis. Neutralisation of $\mathrm{TNF}-\alpha$ results in an attenuation of the cellularity of the parenchyma of the lung, reduces alveolar septal thickening and decreases the disruption of the alveolar architecture, all accompanied by a reduction in fibrosis [95]. In an open pilot study, NIDEN et al. [96] reported tolerability in nine subjects with IPF. Although the subjects were severely ill with $D \mathrm{~L}, \mathrm{CO}<30 \%$ pred, there was a functional improvement in some.

A phase II, double-blind, parallel, placebo-controlled, randomised study of the efficacy and safety of a compound that blocks TNF- $\alpha$ by binding to cell surface receptors inhibiting the initiation of intracellular signalling (Etanercept), in IPF patients is underway. The primary end point of the trial is to evaluate safety and efficacy, with the secondary objective being to evaluate quality of life and pharmacokinetics. The duration is $\sim 80$ weeks and the molecule is given subcutaneously twice a week.

\section{Imatinib mesylate}

Imatinib (STI-571), a c-Abl tyrosine kinase inhibitor that also inhibits activation of the platelet-derived growth factor (PDGF) receptor (PDGF receptor antagonist), significantly reduces bone marrow fibrosis in humans [97]. A phase II, randomised, double blind, placebo-controlled study of the clinical effects of imatinib mesylate administered orally to patients with IPF is currently recruiting patients. The primary end point is disease progression, defined as $>10 \%$ decline in the FVC or death. IPF patients who have not responded to standard therapy will receive imatinib mesylate (600 $\mathrm{mg}$ orally once per day) versus placebo for $\geqslant 2$ yrs.

\section{FG-3019}

An open-label, phase I, safety and tolerability dose-escalating study of FG-3019, a therapeutic antibody designed to block the profibrotic activity of CTGF, is currently underway in IPF patients. CTGF has a cardinal role in IPF pathway by triggering the production of collagen and fibronectin, which cause scarring and thickening of the lungs. The duration of the study is 1 month, during which patients receive a single infusion of FG-3019.

\section{Rapamycin}

Rapamycin (RPM, also known as sirolimus) is a 31-membered macrolide produced from the bacteria Streptomyces hygroscopicus and was found to possess antifungal and immunosuppressive properties. Furthermore, RPM exerts potent antiproliferative effects on lymphoid and nonlymphoid cells by inhibiting cytokine and growth factor-mediated cell signaling [98]. Problems associated with poor bioavailability were overcome with the development of the new orally-active RPM analogue, 40-O-(2-hydroxyethyl)-rapamycin SDZ RAD, which is currently in clinical trials for the prevention of solid organ graft rejection, another condition characterised by excessive extracellular matrix production.

The RPM analogue, SDZ RAD, inhibits growth factordependent proliferation of mesenchymal cells and might, therefore, be of therapeutic interest for the treatment of fibrotic lung disease. It has been recently reported, for the first time, that this agent causes a dramatic (75\%) reduction in lung collagen accumulation in bleomycin-induced pulmonary fibrosis in rats, without any adverse effect on basal collagen levels [99]. Currently, this drug is under evaluation in an open randomised multi-centre trial in Australia. IPF patients are randomised to either sirolimus plus $10 \mathrm{mg} \cdot \mathrm{day}^{-1}$ prednisolone or standard therapy. The sirolimus dose will be titrated to achieve trough levels of $\leqslant 5-8 \mathrm{ng} \cdot \mathrm{mL}^{-1}$ and standard therapy includes imuran $2 \mathrm{mg} \cdot \mathrm{kg}^{-1}$ plus $10 \mathrm{mg}$ prednisolone per day. The study drug will be administered for 26 weeks, with the end points being safety and efficacy. Efficacy will be defined as the absence of disease progression.

\section{Antileukotriene drugs}

Leukotrienes (LTs; lipid mediators of inflammation derived from the 5-lipoxygenase pathway of arachidonic acid metabolism) are profibrotic by induction of fibroblast migration, proliferation and matrix protein synthesis. Patients with IPF have increased lung $\mathrm{LTB}_{4}$ and $\mathrm{LTC}_{4}$ levels, suggesting constitutive activation of the 5-lypoxygenase (5-LO) pathway in this disorder [100]. In 5-LO-null mice, there is increased production of IFN- $\gamma$ and of the anti-inflammatory/antifibrotic eicosanoid, prostaglandin E2, suggesting that the 5-LO pathway may influence the fibrotic response either directly via production of LTs or indirectly by modulating the biosynthesis of other protective mediators [101].

Zileuton, a direct 5-lipoxygenase inhibitor, is currently being evaluated in a prospective, randomised trial at the University of Michigan, MI, USA.

\section{DISCUSSION}

The pharmacological treatment that is currently available for IPF is clearly inadequate. As other forms of pulmonary fibrosis have a better response to immunosuppressive and corticosteroid therapy, it remains vitally important to apply the diagnostic criteria and to follow the proposed treatment recommendations. There is much interest in developing more effective, less toxic pharmacological therapy. A number of high-quality randomised controlled trials are currently under way and clinicians should encourage their patients to address themselves in IPF centres of reference where they have the chance to try new therapeutic agents. The current authors 
suspect that no single approach and no one molecular target will be sufficient.

It is expected that a better approach in demystifying the pathogenesis of IPF could provide a new therapeutic direction for a lethal disease with few therapeutic options. The pathogenetic complexity of the process dictates the need for multimodality therapy. Referral for lung transplantation should be considered in younger patients not responding to conventional treatment.

Future therapeutic strategies should be focused on alveolar epithelial cells at enhancing re-epithelialisation and on fibroblastic/myofibroblastic foci, which play an essential role in the development of idiopathic pulmonary fibrosis. The possible pathogenetic role of circulating fibrocytes should be investigated extensively. The therapeutic prospects for stem cell therapy in regenerating abnormally developed or lost lung tissue, although appear more distant than in some other organs, offer great excitement and hope. The complex, integrated function of multiple cell types underlying normal and fibrotic lung structure and function poses unique challenges for the lung research community.

\section{ACKNOWLEDGEMENTS}

The authors would like to thank H. Moutsopoulos of School of Medicine, National University of Athens (Athens, Greece) for reviewing the manuscript and for his constructive suggestions.

\section{REFERENCES}

1 American Thoracic Society. Idiopathic pulmonary fibrosis: diagnosis and treatment. International consensus statement. Am J Respir Crit Care Med 2000; 161: 646-664.

2 American Thoracic Society. ATS/ERS international multidisciplinary consensus classification of idiopathic interstitial pneumonias. Am J Respir Crit Care Med 2002; 165: 277-304.

3 Bouros D. Current classification of idiopathic interstitial pneumonias. Monaldi Arch Chest Dis 2000; 55: 450-454.

4 Coultas DB, Zumwalt RE, Black WC, Sobonya RE. The epidemiology of interstitial lung diseases. Am J Respir Crit Care Med 1994; 150: 967-972.

5 Hodgson U, Laitinen T, Tukiainen P. Nationwide prevalence of sporadic and familial idiopathic pulmonary fibrosis: evidence of founder effect among multiplex families in Finland. Thorax 2002; 57: 338-342.

6 Hunninghake GW, Zimmerman MB, Schwartz DA, et al. Utility of a lung biopsy for the diagnosis of idiopathic pulmonary fibrosis. Am J Respir Crit Care Med 2001; 164: 1025-1032.

7 Flaherty KR, Thwaite EL, Kazerooni EA, et al. Radiological versus histological diagnosis in UIP and NSIP: survival implications. Thorax 2003; 58: 143-148.

8 Collard HR, King TE Jr. Demystifying idiopathic interstitial pneumonia. Arch Intern Med 2003; 163: 17-29.

9 Selman M, King TE, Pardo A. Idiopathic pulmonary fibrosis: prevailing and evolving hypotheses about its pathogenesis and implications for therapy. Ann Intern Med 2001; 134: 136-151.
10 Flaherty KR, Travis WD, Colby TV, et al. Histopathologic variability in usual and nonspecific interstitial pneumonias. Am J Respir Crit Care Med 2001; 164: 1025-1032.

11 Bouros D, Hatzakis $K$, Labrakis H, Zeibecoglou K. Association of malignancy with diseases causing interstitial pulmonary changes. Chest 2002; 121: 1278-1289.

12 Nicholson AG, Colby TV, du Bois RM, et al. The prognostic significance of the histologic pattern of interstitial pneumonia in patients presenting with the clinical entity of cryptogenic fibrosing alveolitis. Am J Respir Crit Care Med 2000; 162: 2213-2217.

13 Johnston IDA, Prescott RJ, Chalmers JC, Rudd RM, and for the Fibrosing Alveolitis Subcommittee of the Research Committee of the British Thoracic Society. British Thoracic Society study of cryptogeni fibrosing alveolitis: current presentation and initial management. Thorax 1997; 52: 38-44.

14 Gay SE, Kazerooni EA, Toews GB, et al. Idiopathic pulmonary fibrosis: predicting response to therapy and survival. Am J Respir Crit Care Med 1998; 157: 1063-1072.

15 Bjoraker JA, Ryu JH, Edwin MK, et al. Prognostic significance of histopathologic subsets in idiopathic pulmonary fibrosis. Am J Respir Crit Care Med 1998; 157: 199-203.

16 Crystal RG, Bittermann PB, Rennard SI, Hance AJ, Keogh BA. Interstitial lung disease of unknown cause. Disorders characterized by chronic inflammation of the lower respiratory tract. N Engl J Med 1984; 310: 154-166.

17 Gross TJ, Hunninghake GW. Idiopathic pulmonary fibrosis. N Engl J Med 2001; 345: 517-525.

18 Johnson MA, Kwan S, Snell NJC, et al. Randomised controlled trial comparing prednisolone alone with cyclophosphamide and low dose prednisolone in combination in cryptogenic fibrosing alveolitis. Thorax 1989; 44: 280-288.

19 Raghu G, Depaso WJ, Cain K, et al. Azathioprine combined with prednisone in the treatment of idiopathic pulmonary fibrosis: a prospective, double-blind randomized, placebo-controlled clinical trial. Am Rev Respir Dis 1991; 144: 291-296.

20 Winterbauer RH. The treatment of idiopathic pulmonary fibrosis. Chest 1991; 100: 233-235.

21 Douglas WW, Ryu JH, Swensen SJ, et al. Colchicine versus prednisone in the treatment of idiopathic pulmonary fibrosis. A randomized prospective study. Am J Respir Crit Care Med 1998; 158: 220-225.

22 Ziesche R, Hofbauer E, Wittman K, Petkov V, Block L-H. A preliminary study of long-term treatment with interferon gamma-1b and low-dose prednisolone in patients with idiopathic pulmonary fibrosis. N Engl J Med 1999; 341: 1264-1269.

23 Raghu G, Brown K, Bradford W, Starko K, Noble P, Schwartz D. A placebo-controlled trial of interferon gamma-1b in patients with idiopathic pulmonary fibrosis. N Engl J Med 2004; 350: 125-133.

24 Richeldi L, Davies HR, Ferrara G, Franco F. Corticosteroids for idiopathic pulmonary fibrosis. Cochrane Database Syst Rev 2003; 3: CD002880.

25 Flaherty KR, Toews GB, Lynch III JP, et al. Steroids in idiopathic pulmonary fibrosis: a prospective assessment 
of adverse reactions, response to therapy and survival. Am J Med 2001; 110: 278-282.

26 Davies HR, Richeldi L, Walters EH. Immunomodulatory agents for idiopathic pulmonary fibrosis. Cochrane Database Syst Rev 2003; 3: CD003134.

27 Fulmer J, Elson N, Von Gal E, et al. Treatment of idiopathic pulmonary fibrosis. Clin Res 1978; 26: 538A.

28 Cegla UH, Kroidl RF, Meier-Sydow J, et al. Therapy of idiopathic fibrosis of the lung. Experiences with three therapeutic principles: corticosteroids in combination with azathioprine, D-penicillamine and para-aminobenzoate. Pneumonolgie 1975; 152: 75-92.

29 Costabel U, Matthys H. Different therapies and factors influencing response to therapy in idiopathic diffuse fibrosing alveolitis. Respiration 1981; 42: 141-149.

30 Brown $\mathrm{CH}$, Turner-Warwick $\mathrm{M}$. The treatment of cryptogenic fibrosing alveolitis with immunosuppressant drugs. Quart J Med 1971; 40: 289-302.

31 Meier-Sydow J, Rust M, Kronenberger H. Survival of patients with idiopathic pulmonary fibrosis following treatment with azathioprine, D-penicillamine or prednisolone: ten-year follow-up. Chest 1990; 98: 18S.

32 Shishido M, Ichiki H, Yano M, et al. A case of idiopathic pulmonary fibrosis with histology of usual interstitial pneumonia that responded to pulse therapy followed by combined immunosuppression with prednisolone and azathioprine. Japan J Thorac Dis 1992; 30: 2139-2145.

33 Weese WC, Levine BW, Kazemi H. Interstitial lung disease resistant to corticosteroid therapy: report of three cases treated with azathioprine or cyclophosphamide. Chest 1975; 67: 57-60.

34 Winterbauer RH, Hammar SP, Hallman KO, et al. Diffuse interstitial pneumonitis: clinicopathologic correlations in 20 patients treated with prednisone/azathioprine. Am J Med 1978; 65: 661-672.

35 Meier-Sydow J, Rust M, Kronenberger H, et al. Long-term follow-up of lung function with parameters in patients with idiopathic pulmonary fibrosis treated with prednisone and azathioprine or D-penicillamine. Prax Pneumonol 1979; 33: 680-688.

36 Baughman RP, Lower EE. Use of intermittent intravenous cyclophosphamide for idiopathic pulmonary fibrosis. Chest 1992; 102: 1090-1094.

37 Behr J, Adelmann-Grill BC, Krombach F, et al. Fibroblast chemotactic response elicited by native bronchoalveolar lavage fluid from patients with fibrosing alveolitis. Thorax 1993; 48: 736-742.

38 Dayton CS, Schwartz DA, Helmers RA, et al. Outcome of subjects with idiopathic pulmonary fibrosis who fail corticosteroid therapy: implications for further studies. Chest 1993; 103: 69-73.

39 Eliasson O, Cole SR, Degraff A. Adverse effects of cyclophosphamide in idiopathic pulmonary fibrosis. Conn Med 1985; 49: 286-289.

40 Meuret G, Fueter R, Gloor F. Early stage of fulminant idiopathic pulmonary fibrosis cured by intense combination therapy using cyclophosphamide, vincristine, and prednisone. Respiration 1978; 36: 228-233.

41 O’Donnell K, Keogh B, Cantin A, Crystal RG. Pharmacologic suppression of the neutrophil component of the alveolitis in idiopathic pulmonary fibrosis. Am Rev of Respir Dis 1987; 136: 288-292.

42 Van Oortegem K, Wallaert B, Marquette $\mathrm{CH}$, et al. Determinants of response to immunosuppressive therapy in idiopathic pulmonary fibrosis. Eur Respir J 1994; 7: 1950-1957.

43 Schwartz DA, Helmers RA, Galvin JR, et al. Determinants of survival in idiopathic pulmonary fibrosis. Am J Respir Crit Care Med 1994; 149: 450-454.

44 Zisman DA, Lynch JP, Toews GB, et al. Cyclophosphamide in the treatment of idiopathic fibrosis: a prospective study in patients who failed to respond to corticosteroids. Chest 2000; 117: 1619-1626.

45 Kolb M, Kirschner J, Riedel W, et al. Cyclophosphamide pulse therapy in idiopathic pulmonary fibrosis. Eur Respir J 1998; 12: 1409-1414.

46 Collard HR, Ryu JH, Douglas WW, et al. Combined corticosteroid and cyclophosphamide therapy does not alter survival in idiopathic pulmonary fibrosis. Chest 2004; 125: 2169-2174.

47 Kondoh Y, Taniguchi H, Yokoi $\mathrm{T}$, et al. Cyclophosphamide and low-dose prednisolone in idiopathic pulmonary fibrosis and fibrosing nonspecific interstitial pneumonia. Eur Respir J 2005; 25: 528-533.

48 Alton EWFW, Johnson M, Turner-Warwick M. Advanced cryptogenic fibrosing alveolitis: preliminary report on treatment with cyclosporin A. Respir Med 1989; 83: 277-279.

49 Fukazawa M, Kawano M, Hisano S, et al. Efficacy of cyclosporine A for idiopathic pulmonary fibrosis. Eur J Paed 1990; 149: 441-442.

50 Moolman JA, Bardin PG, Rossouw DJ, Joubert JR. Cyclosporin as a treatment for interstitial lung disease of unknown aetiology. Thorax 1991; 46: 592-595.

51 Venuta F, Rendina EA, Ciriaco P, et al. Efficacy of cyclosporine to reduce steroids in patients with idiopathic pulmonary fibrosis before lung transplantation. $J$ Heart Lung Transplant 1993; 12: 909-914.

52 Inase N, Sawada M, Ohtani Y, et al. Cyclosporine A followed by the treatment of acute exacerbation of idiopathic pulmonary fibrosis with corticosteroid. Intern Med 2003; 42: 565-570.

53 Altschuler EL. Consideration of mycophenolate mofetil for idiopathic pulmonary fibrosis. Med Hypotheses 2001; 57: 701-702.

54 Gross DC, Sasaki TM, Buick MK, Light JA. Acute respiratory failure and pulmonary fibrosis secondary to administration of mycophenolate mofetil. Transplantation 1997; 64: 1607-1609.

55 Morrissey P, Gohh R, Madras P, Monaco AP. Pulmonary fibrosis secondary to administration of mycophenolate mofetil. Transplantation 1998; 65: 1414.

56 Lynch III JP, McCune WJ. Immunosuppressive and cytotoxic pharmacotherapy for pulmonary disorders. Am J Respir Crit Care Med 1997; 155: 395-420.

57 Douglas ID, Price LA. Bone-marrow toxicity of methotrexate; a reassessment. Br J Haematol 1973; 24: 625-631.

58 Antoniades HN, Bravo MA, Avila RE, et al. Plateletderived growth factor in idiopathic pulmonary fibrosis. $J$ Clin Invest 1990; 86: 1055-1064. 
59 Kapanci Y, Desmouliere A, Pache JC, et al. Cytoskeletal protein modulation in pulmonary alveolar myofibroblasts during idiopathic pulmonary fibrosis: possible role of transforming growth factor beta and tumor necrosis factor alpha. Am J Respir Crit Care Med 1995; 152: 2163-2169.

60 Khalil N, O'Connor RN, Unruh HW, et al. Increased production and immunohistochemical localization of transforming growth factor-beta in idiopathic pulmonary fibrosis. Am J Respir Cell Mol Biol 1991; 5: 155-162.

61 Nash JR, McLaughlin PJ, Butcher D, et al. Expression of tumour necrosis factor-alpha in cryptogenic fibrosing alveolitis. Histopathology 1993; 22: 343-347.

62 Pan LH, Yamauchi K, Uzuki M, et al. Type II alveolar epithelial cells and interstitial fibroblasts express connective tissue growth factor in IPF. Eur Respir J 2001; 17: 1220-1227.

63 Giaid A, Michel RP, Stewart DJ, et al. Expression of endothelin-1 in lungs of patients with cryptogenic fibrosing alveolitis. Lancet 1993; 341: 1550-1554.

64 Murphy G, Stanton H, Cowell S, et al. Mechanisms of promatrix metalloproteinase activation. APMIS 1999; 107: $38-44$.

65 Legrand C, Polette M, Tournier JM, et al. uPA/plasmin system-mediated MMP-9 activation is implicated in bronchial epithelial cell migration. Exp Cell Res 2001; 264: 326-336.

66 Gandossi E, Lunven C, Berry CN. Role of clot-associated (-derived) thrombin in cell proliferation induced by fibrin clots in vitro. Br J Pharmacol 2000; 129: 1021-1027.

67 Plataki M, Koutsopoulos A, Darivianaki K, Delides G, Siafakas N, Bouros D. Expression of apoptotic and antiapoptotic markers in epithelial cells in idiopathic pulmonary fibrosis. Chest 2005; 127: 266-274.

68 Jordana M, Schulman J, McSharry C, et al. Heterogeneous proliferative characteristics of human adult lung fibroblast lines and clonally derived fibroblasts from control and fibrotic tissue. Am Rev Respir Dis 1988; 137: 579-584.

69 Selman M, Pardo A. Idiopathic pulmonary fibrosis: an epithelial/fibroblastic cross-talk disorder. Respir Res 2002; 3: 3.

70 Phillips RJ, Burdick MD, Hong K, et al. Circulating fibrocytes traffic to the lungs in response to CXCL12 and mediate fibrosis. J Clin Invest 2004; 114: 438-446.

$71 \mathrm{du}$ Bois RM. Interferon gamma-1b for the treatment of idiopathic pulmonary fibrosis. N Engl J Med 1999; 341: 1302-1304.

72 Strieter RM, Starko KM, Enelow RI, Noth I, Valentine VG. Effects of interferon gamma-1b on biomarker expression in idiopathic pulmonary fibrosis patients. Am J Respir Crit Care Med 2004; 170: 133-140.

73 Antoniou KM, Alexandrakis M, Sfiridaki K, et al. Th1 cytokines (IL-12 and IL-18) in bronchoalveolar lavage fluid before and after treatment with interferon gamma$1 \mathrm{~b}$ or colchicine in idiopathic pulmonary fibrosis. Sarcoidosis Vasc Diffuse Lung Dis 2004; 21: 105-110.

74 King TE Jr, Safrin S, Starko KM, et al. Analyses of efficacy end points in a controlled trial of interferon-gamma1b for idiopathic pulmonary fibrosis. Chest 2005; 127: 171-177.

75 Douglas WW, Ryu JH, Schroeder DR. Idiopathic pulmonary fibrosis: impact of oxygen and colchicine, prednisone, or no therapy on survival. Am J Respir Crit Care Med 2000; 161: 1172-1178.

76 Douglas WW, Ryu JH, Bjoraker JA, et al. Colchicine versus prednisone as treatment of usual interstitial pneumonia. Mayo Clin Proc 1997; 72: 201-209.

77 Selman M, Carrillo G, Salas J, et al. Colchicine, Dpenicillamine, and prednisone in the treatment of idiopathic pulmonary fibrosis: a controlled clinical trial. Chest 1998; 114: 507-512.

78 Ward WF, Shih-Heollwarth A, Tuttle RD. Collagen accumulation in irradiated rat lung: modification by $\mathrm{D}$ penicillamine. Radiology 1983; 146: 533-537.

79 Goodman M, Turner-Warwick M. Pilot study of penicillamine therapy in corticosteroid failure patients with widespread pulmonary fibrosis. Chest 1978; 74: 338.

80 Goodman M, Knight RK, Turner-Warwick M. Pilot studies of penicillamine therapy in steroid failure patients with interstitial lung disease. In: Maini RN, Berry H, eds. Modulation of Autoimmunity and Disease. Prague, Praeger, 1981; pp. 291-300.

81 Rudd RM, Haslam PL, Turner-Warwick M. Cryptogenic fibrosing alveolitis: relationships of pulmonary physiology and bronchoalveolar lavage to response to treatment and prognosis. Am Rev Respir Dis 1981; 124: 1-8.

82 Chapela R, Zuniga G, Selman M. D-penicillamine in the therapy of fibrotic lung diseases. Int J Clin Pharmacol Ther Toxicol 1986; 24: 16.

83 Kaneko M, Inoue $\mathrm{H}$, Nakazawa $\mathrm{R}$, et al. Pirfenidone induces intercellular adhesion molecule-1 (ICAM-1) down-regulation on cultured human synovial fibroblasts. Clin Exp Immunol 1998; 113: 72-76.

84 Raghu G, Johnson WC, Lockhart D, Mageto Y. Treatment of idiopathic pulmonary fibrosis with a new antifibrotic agent, pirfenidone: results of a prospective, open-label Phase II study. Am J Respir Crit Care Med 1999; 159: 1061-1069.

85 Nagai S, Hamada K, Shigematsu M, Taniyama M, Yamauchi S, Izumi T. Open-label compassionate use one year-treatment with pirfenidone to patients with chronic pulmonary fibrosis. Intern Med 2002; 41: 1118-1123.

86 Azuma A, Nukiwa T, Tsuboi E, et al. Double-blind, placebo-controlled trial of pirfenidone in patients with idiopathic pulmonary fibrosis. Am J Respir Crit Care Med 2005; 171: 1040-1047.

87 Nadrous HF, Ryu JH, Douglas WW, Decker PA, Olson EJ. Impact of angiotensin-converting enzyme inhibitors and statins on survival in idiopathic pulmonary fibrosis. Chest 2004; 126: 438-446.

88 MacNee W, Rahman I. Oxidants/antioxidants in idiopathic pulmonary fibrosis. Thorax 1995; 50: Suppl. 1, S53-S58.

89 Meyer A, Buhl R, Magnussen H. The effect of oral Nacetylcysteine on lung glutathione levels in idiopathic pulmonary fibrosis. Eur Respir J 1994; 7: 431-436.

90 Behr J, Maier K, Degenkolb B, Krombach F, Vogelmeier C. Antioxidative and clinical effects of high-dose N-acetylcysteine in fibrosing alveolitis: adjunctive therapy to maintenance immunosuppression. Am J Respir Crit Care Med 1997; 156: 1897-1901. 
91 Saleh D, Furukawa K, Tsao MS, et al. Elevated expression of endothelin-1 and endothelin-converting enzyme-1 in idiopathic pulmonary fibrosis: possible involvement of proinflammatory cytokines. Am J Respir Cell Mol Biol 1997; 16: 187-193.

92 Park SH, Saleh D, Giaid A, Michel RP. Increased endothelin-1 in bleomycin-induced pulmonary fibrosis and the effect of an endothelin receptor antagonist. Am J Respir Crit Care Med 1997; 156: 600-608.

93 Salani D, Taraboletti G, Rosano L, et al. Endothelin-1 induces an angiogenic phenotype in cultured endothelial cells and stimulates neovascularization in vivo. Am J Pathol 2000; 157: 1703-1711.

94 O'Callaghan D, Gaine SP. Bosentan: a novel agent for the treatment of pulmonary arterial hypertension. Int J Clin Pract 2004; 58: 69-73.

95 Piguet PF, Ribaux C, Karpuz V, et al. Expression and localization of tumor necrosis factor-alpha and its mRNA in idiopathic pulmonary fibrosis. Am J Pathol 1993; 143: 651-655.
96 Niden A, Koss MN, Boylen CT, et al. An open label pilot study to determine the potential efficacy of TNFR: FC (Enbrel, etanercept) in the treatment of usual interstitial pneumonitis. Am J Respir Crit Care Med 2002; 165: A728.

97 Buchdunger E, O'Reilly T, Wood J. Pharmacology of imatinib (STI571). Eur J Cancer 2002; 38: Suppl. 5, S28-S36.

98 Sehgal SN. Rapamune (RAPA, rapamycin, sirolimus): mechanism of action immunosuppressive effect results from blockade of signal transduction and inhibition of cell cycle progression. Clin Biochem 1998; 31: 335-340.

99 Simler NR, Howell DCJ, Marshall RP, et al. The rapamycin analogue SDZ RAD attenuates bleomycininduced pulmonary fibrosis in rats. Eur Respir J 2002; 19: 1124-1127.

100 Peters-Golden M, Bailie M, Marshall T, et al. Protection from pulmonary fibrosis in leukotriene-deficient mice. Am J Respir Crit Care Med 2002; 165: 229-235.

101 Riccioni G, Di Ilio C, Conti P, Theoharides T, D'Orazio N. Advances in therapy with antileukotriene drugs. Ann Clin Lab Sci 2004; 34: 379-387. 